\title{
Methane Desorption from Homogeneous Distributed Micro-Pores of Coal
}

\author{
Wei Liu, Zhenxin Yan* \\ Department of Applied Physics, Xi'an University of Science and Technology, Xi'an, China \\ Email: ${ }^{*}$ hhengxinyan163@163.com
}

Received 12 May 2015; accepted 14 June 2015; published 17 June 2015

Copyright (C) 2015 by authors and Scientific Research Publishing Inc.

This work is licensed under the Creative Commons Attribution International License (CC BY). http://creativecommons.org/licenses/by/4.0/

(c) () Open Access

\begin{abstract}
The thermal desorption kinetic mechanism from internal micro-pores of coal is theoretically investigated by Monte Carlo simulations. It is supposed that the molecules are absorbed in the pores and can jump between adjacent ones. The desorption rates of the statistical ensemble average are calculated. The competing effect of the temperature and the adsorptive energy is analyzed. The desorption probabilities indicated that the choice of desorption energy is clear at low temperature, however, there is not clearly different between high temperature.
\end{abstract}

Keywords

Desorption, Coal-Bed, Lattice-Gas Model, Monte Carlo Simulation

\section{Introduction}

Coal-bed methane, the major constituent of natural gas is mainly in the adsorption phase, solid or liquid state, in different pores of coal under under-earth reservoir conditions [1]-[3]. Methane existing in coal-pore will be desorbed for outer-disturbing, such as temperature, pressure or optic induced etc. [1]-[5]. The emission of flammable gases, predominantly methane from coal-beds with the increasing temperature, has always been a major problem for storage of coal. Meanwhile, methane has the highest H/C ratio, and consequently a higher research octane number than other fuels, which is a potential succedaneum for petroleum fuel. Coal-bed gas is also considered as potential causation leading to serious safety accidents in coal mines due to gas burst [4] [5], and energy loss and global climate effect due to its emission. In addition to the coal-bed systems, many researchers have performed experiments to investigate the desorption kinetic process under pressure or temperature program in varieties of systems [6]-[10]. Their problem solving approach and the methodology are impressive, and would be applied to dealing with desorption of coal-bed methane.

${ }^{*}$ Corresponding author.

How to cite this paper: Liu, W. and Yan, Z.X. (2015) Methane Desorption from Homogeneous Distributed Micro-Pores of Coal. Journal of Applied Mathematics and Physics, 3, 643-648. http://dx.doi.org/10.4236/jamp.2015.36077 
For a long time, scholars have emphasized on the researches of coal-bed methane characteristics and have paid little attention to the desorption characteristics during coal-bed methane production [3]-[5]. The micromechanism of methane desorption with temperature program is key knot to evaluate the safety of piling coal. Simultaneously conducted theoretical analysis on desorption and adsorption processes, is the basis for a consideration of the mechanism of depositing of vapors and gases in the coal structure. However, few researches, especially taking the absorbed state of methane on the different positions, could be in good agreement with the experimental results.

The aim of the present study is to determine the desorption kinetic detail of methane by analysis of the desorption with temperature program, which provides further insight into the desorption mechanism. Although besides methane, ethane and carbon dioxide are present to a small extent in the seam gas, their dissolved fraction can be considered negligible compared to methane, and thus this study focuses on the absorption of methane solely.

In Section 2 we present the theoretical model and the simulation method and in Section 3, we give results of the simulations and make some discussions. Section 4 is the conclusion.

\section{Theoretical Model and Simulation Method}

To study the kinetic behavior of the desorption, many authors use Lattice gas model [11]-[13] which is a collection of atoms that may take on discrete positions. A configuration of the lattice is defined by site occupation variables $n_{i}$, where $n_{i}=1$ or 0 represents the site is occupied or not. The Hamiltonian of the model is

$$
H=\sum_{i} e_{i} n_{i}+\sum_{\langle i j\rangle} v_{i j} n_{i} n_{j}
$$

where $e_{i}$ is the adsorptive energy of atoms, and $v_{i j}$ denotes the molecule interaction of the nearest neighbors. However, the structure of the coal-bed is very complicated. There are lots of micro-pores, meso-pores and macro-pores in the coal. The micro-pores in coal are estimated to have diameters ranging from 0.5 to $3 \mathrm{~nm}$ and occur as part of the coal matrix. In this article, we focus on the methane desorption mechanism from micro-pores, which can deposit several methane molecules. The methane is adsorbed in the pores at low temperature. As the temperature increasing, the molecules of the methane will be desorbed from the micro-pores. In order to study the kinetic process, we generalize the Hamiltonian by adding an on-site interaction:

$$
H=\sum_{i} e_{i} n_{i}+\sum_{i} v_{0} n_{i}\left(n_{i}-1\right)+\sum_{i j} v_{i j} n_{i} n_{j}
$$

where $n_{i}$ is the number of the molecules in the $\mathrm{i}_{\text {th }}$ pore, $v_{0}$ is the repulsive interaction when the molecules are in the same micro-pore and $v_{i j}$ denotes the molecule interaction of the different micro-pores. If the distance of the adjacency pores is far enough, the interaction of the molecular is small. In this case, $v_{i j}=0$. In addition, we define the density of the molecular number, $\theta=\sum_{i} \frac{n_{i}}{N}$ where $N$ is the number of the micro-pores.

In our work, the Monte Carlo simulation is applied to analyze the detail of the desorption kinetic process of temperature program. For simplicity, we investigate one dimension chain. If the temperature is increasing with a constant rate, the probability for the desorption in temperature interval $\Delta T$ is,

$$
p(\Delta T)=\beta \Delta T \exp (-H / R T)
$$

where $\beta$ is a parameter related with the rate of the increasing temperature and the structure of the coal, and $R$ is the universal gas constant. For the molecules may jump form one pore to another, we should give a jumping mechanism, which a molecular jump to its adjacency according to the probability $P=\exp \left(\left|E_{i}-E_{f}\right| / R T\right)$.

\section{Results and Discussion}

At first, it is considered that the interactions of different micro-pores might be very weak because of the long distant between them, therefore, we let $v_{i j}=0$. The desorption kinetic process of methane molecules from the internal surface of coal was simulated with one dimensional chain during 200 - $460 \mathrm{~K}$. We checked our theoretical model by tuning the absorption energy, from $40 \mathrm{~kJ} / \mathrm{mol}$ to $60 \mathrm{~kJ} / \mathrm{mol}$ to evaluate to the difficulty of the methane molecules with different energy at different point, as shown in Figure 1. The predicted desorption tem- 


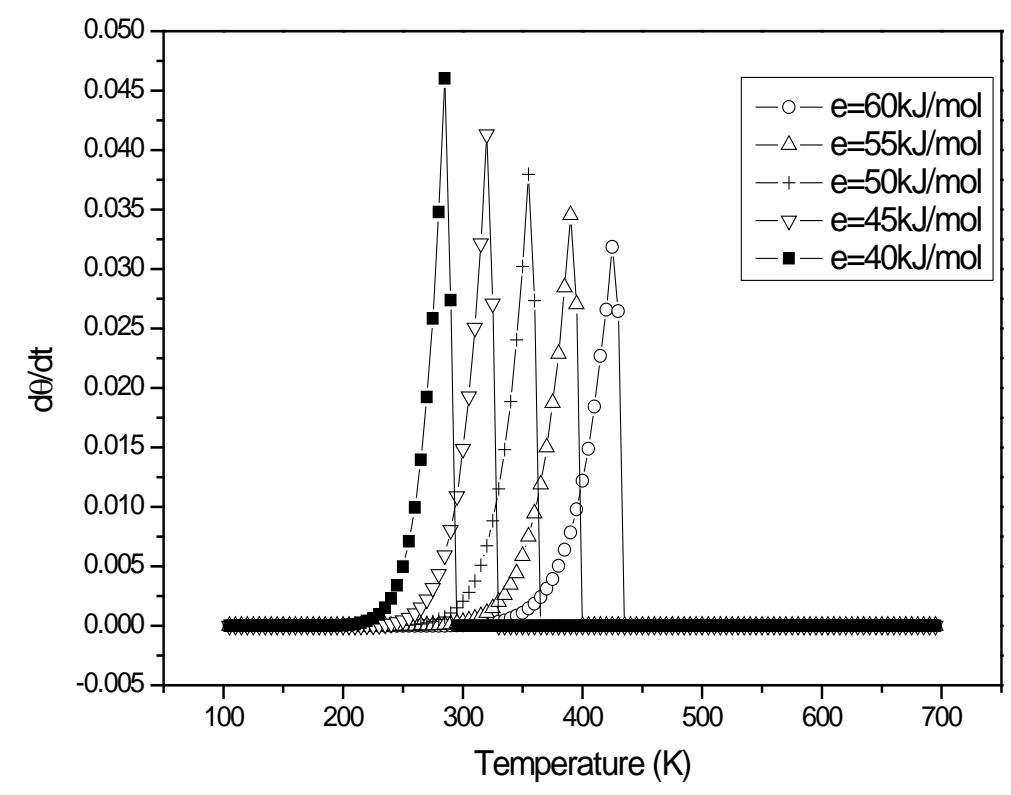

Figure 1. Homogeneous linear chain, variation without nearest-neighbor interaction energy.

peratures are basically in agreement with experimental one [14], however, the desorption kinetic process behind the peak is extraordinary (abnormal).

The interaction between molecules, especially the jumping in the nearest-neighbor should be taken account in our model. If the condition of temperature or pressure changes, the kinetic energy of thermal vibration increases, making the gas molecule escape from the inner surface of the coal block by overcoming gravitation field and by becoming a free phase. The simulating results with jumping of nearest-neighbor indicated that it is reasonable, as shown in Figure 2. The methane structure in one-dimensional chain is a well-characterized adsorbate system, ideal for the study of fundamental surface desorption processes. It also constitutes the basis for the theoretical analysis of the thermodynamics of coal-sorbate systems and both enthalpy and entropy change in the adsorption process with respect to the specifics of coal structure.

To describe the desorption characters, we draw the desorption curve of $e=55 \mathrm{~kJ} / \mathrm{mol}$ in detail with different temperature regions in Figure 3. The result shows that at low temperature section, which corresponds to the temperature region 210 - $230 \mathrm{~K}$, there is no significant variation in desorption rate. The absorbing heating is lower than the desorption active energy of methane absorbed on the internal surface of the pore and fissuring of coal, that is that there an equilibrium of absorption and desorption. However, the vibration of the absorbed molecules on the internal surface will become increasingly sharpen for increasing absorbing heating and the collision of other molecules, meanwhile the diffuse rate will also increase for the increasing pressure in pore and fissuring of coal, which will cause a high exponential desorption kinetic process during 260 - $350 \mathrm{~K}$. The probabilities of the velocity distribution of methane molecules at designed temperature also support the point, as shown in Figure 4. The molecules with high velocity will increase clearly with increasing temperature, the probability of collision will also be enhanced, then the desorption rate will also be increased.

Taking the coal sample as an example, the desorption energy of methane is taken $55 \mathrm{~kJ} / \mathrm{mol}$, then the desorption probability of it is obtained, as shown in Figure 5. The beginning temperature of desorption is room temperature, which consist with the desorption temperature in coal mine. The desorption rate increases violently over $360 \mathrm{~K}$, which is extremely agreement with our previous experiment.

To identify the desorption difficulty of methane molecules at different energy point, the releasing probabilities at different temperatures were presented in logarithmic form, as shown in Figure 6. The desorption probabilities at $300 \mathrm{~K}, 350 \mathrm{~K}$ and $400 \mathrm{~K}$, which have approximately same slope, are nearly similar behavior. Consequently, the choice of desorption will not be mainly effect with increasing temperature. However, the choice of desorption is clear at $200 \mathrm{~K}$, that is those methane molecules with low desorption energy will easily be released at low temperature. 


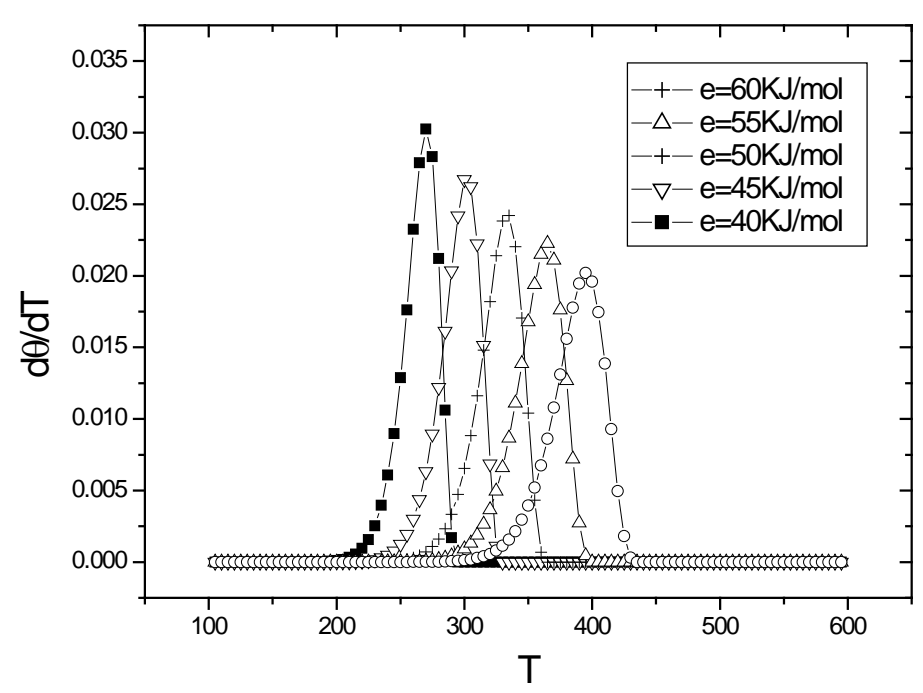

Figure 2. Homogeneous linear chain, variation with near-neighbor jumping interaction energy.
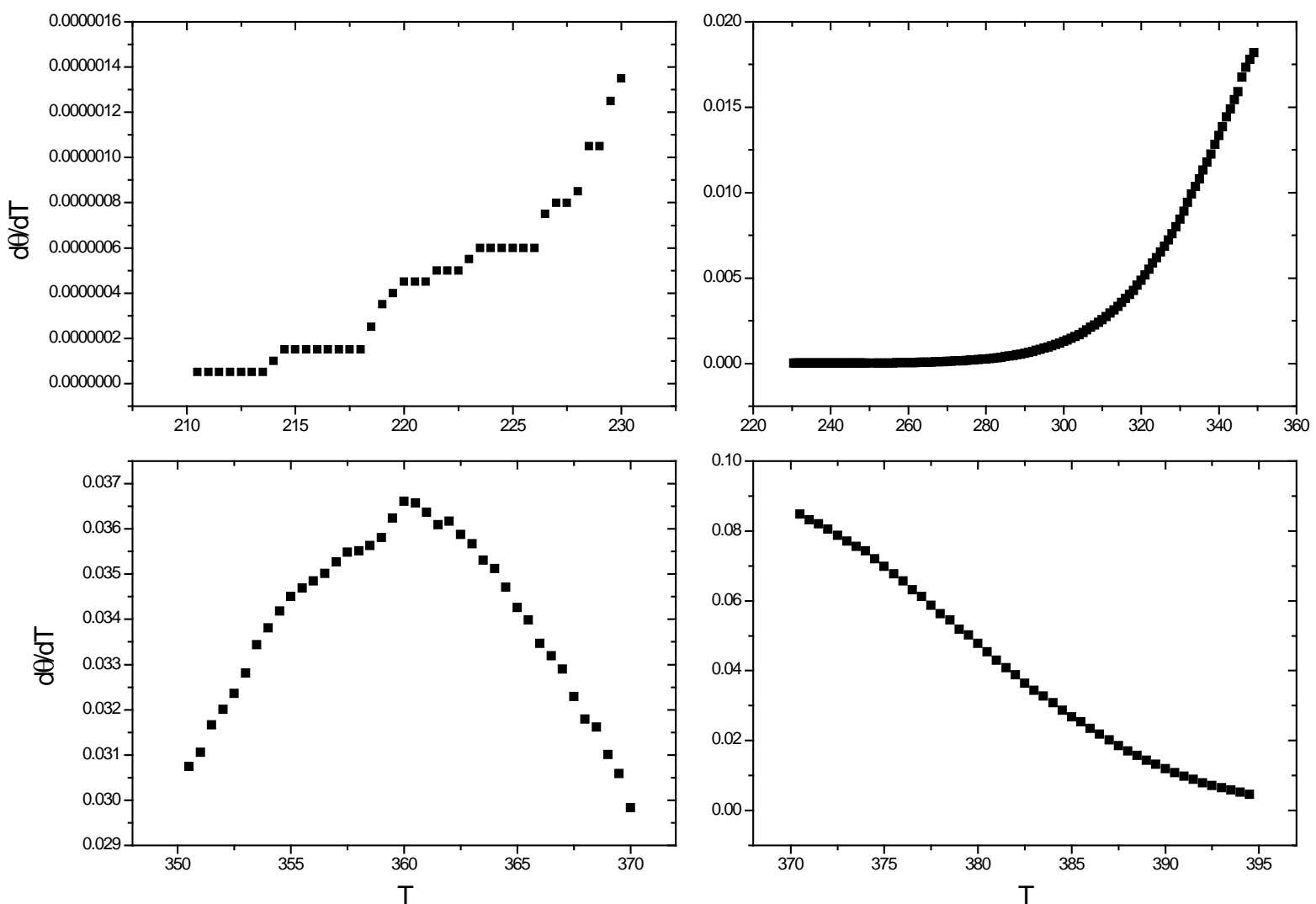

Figure 3. The desorption characteristic in detail with different temperature regions.

\section{Conclusion}

The models for one-dimension chain which is based on the jumping nearest-neighbor molecules is an appropriate method to discuss the kinetic process of thermal desorption of adsorbed molecules on the internal surface of coal. The thermal desorption mechanism is different from the pressure one. Analyzing the desorption curves of different adsoptive energy, we find that the initial desorption temperatures can be strongly affected by adsorp- 


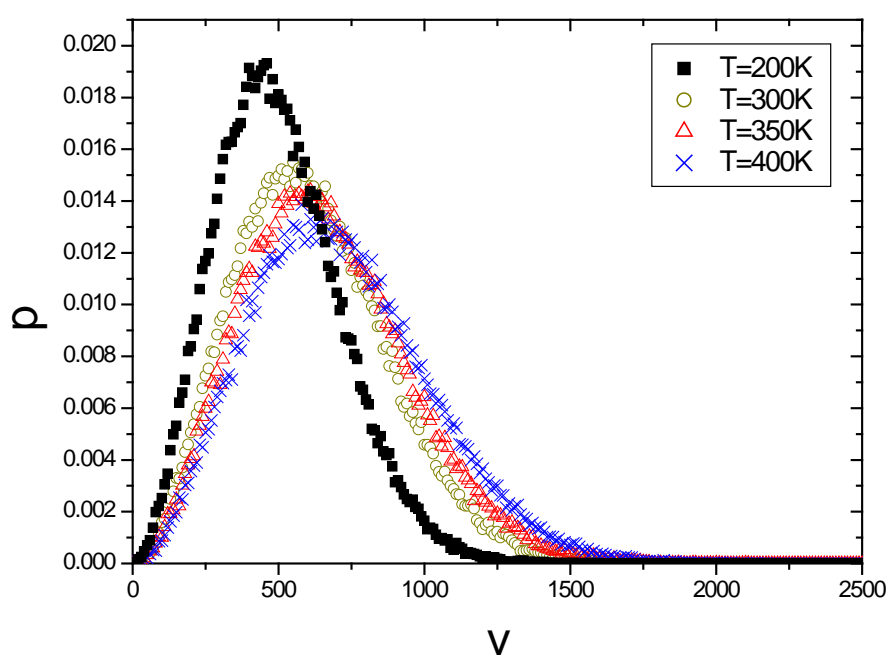

Figure 4. The velocity distribution of methane in lattice with different temperatures.

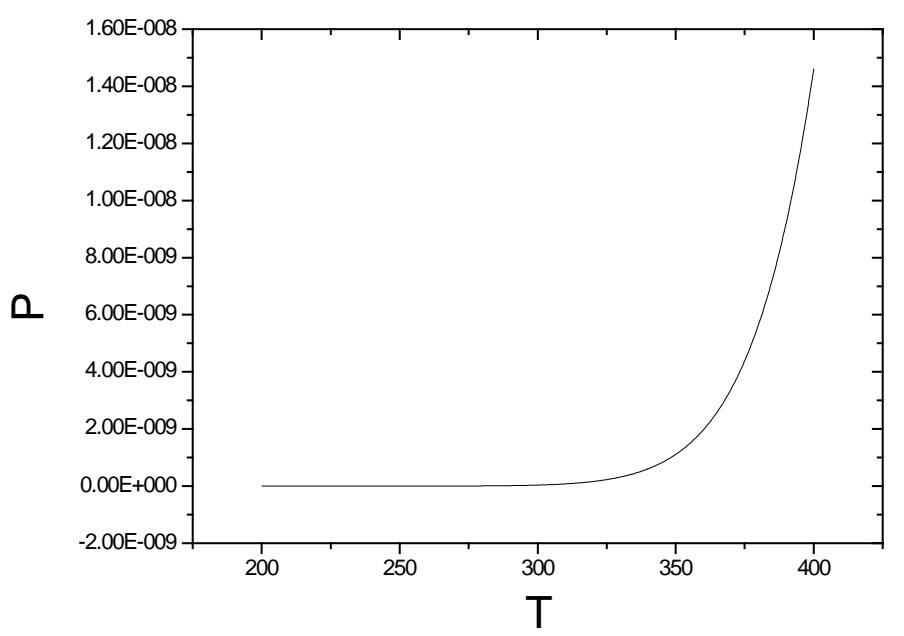

Figure 5. The desorption probabilities of methane with desorption energy, $55 \mathrm{~kJ} / \mathrm{mol}$.

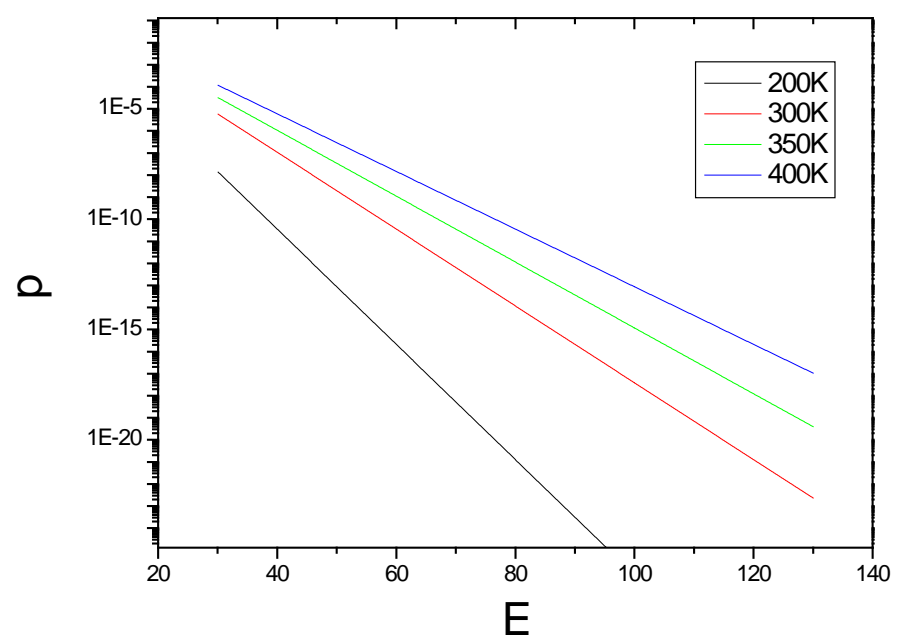

Figure 6. The choice of methane with different desorption energy. 
tion energy of molecules. In addition, the desorption probabilities shows that, at low temperature, the desorption molecules is of low energy, however, for the virbration and collision of other ambient molecules increasing, the energy of the molecules desorbed from coal is much higher in high temperature. Although the conclusions which are agreement with the experiment, are get in the article, for the coal-bed is of very complicated structure, one-dimension micro-pore chain could not describe the system precisely. Hence, more complex models, such as 2D/3D structures, complex networks and some heterogeneous structure in different dimensions, are needed to be further studied.

\section{Acknowledgements}

The work is supported by the Natural Science Foundation of China under Grant No. 11405127 and Scientific Research Program Funded by Shaanxi Provincial Education Commission Program No. 12JK095.

\section{References}

[1] Crosdale, P.J., Beamish, B.B. and Valix, M. (1998) Coal-Bed Methane Sorption Related to Coal Composition. International Journal of Coal Geology, 35, 147-158. http://dx.doi.org/10.1016/S0166-5162(97)00015-3

[2] Li, J., Liu, F., Wang, H. and Zhou, W. (2008) Desorption Characteristics of Coal-Bed Methane Reservoirs and Affecting Factors. Petroleum Exploration and Development, 35, 52-58. http://dx.doi.org/10.1016/S1876-3804(08)60008-7

[3] Hower, J.C., Trinkle, E.J. and Raione, R.P. (2008) Vickers Microhardness of Telovitrinite and Pseudovitrinite from High Volatile Bituminous Kentucky Coals. International Journal of Coal Geology, 75, 76-80. http://dx.doi.org/10.1016/j.coal.2008.03.002

[4] Harpalani, S. and Chen, G. (1995) Estimation of Changes in Fracture Porosity of Coal with Gas Emission. Fuel, 74, 1491-1498. http://dx.doi.org/10.1016/0016-2361(95)00106-F

[5] Salehi, E., Taghikhani, V., Ghotbi, C., Lay, E.N. and Shojaei, A. (2007) Theoretical and Experimental Study on the Adsorption and Desorption of Methane by Granular Activated Carbon at $25^{\circ}$ C. Journal of Natural Gas Chemistry, 16, 415-422. http://dx.doi.org/10.1016/S1003-9953(08)60014-6

[6] Kurlenya, M.V. and Serdyukov, S.V. (2010) Methane Desorption and Migration in Thermodynamic Inequilibrium Coal Beds. Journal of Mining Science, 46, 50-56. http://dx.doi.org/10.1016/0370-1573(78)90143-6

[7] Douglas, J.F., Johnson, H.E. and Granic, S. (1993) Simple Kinetic Model of Polymer Adsorption and Desorption. Science, 262, 2010-2012. http://dx.doi.org/10.1126/science.262.5142.2010

[8] Rochoux, M., Guo, Y., Schuurman, Y. and Farrusseng, D. (2015) Determination of Oxygen Adsorption-Desorption Rates and Diffusion Rate Coefficients in Perovskites at Different Oxygen Partial Pressures by a Microkinetic Approach. Physical Chemistry Chemical Physics, 17, 1469-1481. http://dx.doi.org/10.1039/C4CP04243C

[9] Manzi, S.J., Huespe, V.J., Belardinelli, R.E. and Pereyra, V.D. (2009) Hard versus Soft Dynamics for Adsorption-Desorption Kinetics: Exact Results in One-Dimension. Physical Review E, 80, 051112. http://dx.doi.org/10.1103/PhysRevE.80.051112

[10] Szabelskia, P., Panczyk, T. and Rudzinski, W. (2009) Theoretical Study of the Influence of Laser-Induced Defectson the Adsorption of Gases on Solid Surfaces. Applied Surface Science, 252, 582-590.

http://dx.doi.org/10.1016/j.apsusc.2005.02.072

[11] Dash, J.G. (1978) Helium Films from Two to Three Dimension. Physics Reports, 38C, 177-226. http://dx.doi.org/10.1016/0370-1573(78)90143-6

[12] Binder, K. and Landau, D.P. (1980) Phase Diagrams and Critical Behavior in Ising Square Lattices with Nearest- and Next-Nearest-Neighbor Interactions. Physical Review B, 21, 1941. http://dx.doi.org/10.1103/PhysRevB.21.1941

[13] Yin, J. and Landau, D.P. (2010) Square Lattcie Gases with Tow- and There Body Interactions Revisited: A RowShifted $(2 \times 2)$ Phase. Physical Review E, 81, 031121. http://dx.doi.org/10.1103/PhysRevE.81.031121

[14] Deng, J., Yan, Z.X. and Liu, W. (2015) An Experimental Study of Desorbing Kinetic Process of Methane. Unpublished. 